\title{
Dealing with doxies
}

Writes Paul Thompson of Shrewsbury, England: 'Magazines often say that the opinions expressed in articles are not necessarily those of the editor, that the magazine is a forum. So far, those whose doxy is orthodoxy seem to receive short shrift in $E T$, and come in for the "sic" treatment if they blunder, or for the editorial equivalent of a pat on the head. Am I being unfair? Is it time for a regular "ortho-slot", I wonder, to restore balance and to retain readers?"

Paul Thompson's comment has some justification. There is a broad liberal quality to the material in $E T$, whatever its provenance, and that quality inevitably melds with the interests and biases of editor and consulting editor. At the same time, however, David Crystal and I have been looking for some kind of 'ortho-slot' since $E T$ came into existence.

Not that there has been any shortage of material coming in from the ultra-orthodox, especially in the first year of publication, when numbers of people, especially in the United Kingdom, took the view that English Today was created to defend a certain kind of citadel. The problem with this material, as we have tried to show from time to time, is that it is frequently angry, embattled, disjointed and linguistically ill-informed. To have published it in any quantity would have destroyed $E T$ 's reputation at a stroke in the world of scholarship.

However, as we have always insisted, traditionalism in language is important, and has an honoured place in any magazine that purports to review the whole spectrum of linguistic life. As a consequence, while we aim to be varied in every issue, this issue concentrates on what Paul Thompson calls 'orthodoxy'.

In my cover feature, I first of all look at the nature of English in global terms (in both senses of that word), then in individual terms - particularly those individuals who responded to my invitation in the editorial of ET8 last

\section{Promoting English Today}

ET readers know a lot of people all over the world. Such people are connected with:

libraries
schools
colleges
universities
professional associations
business companies
communications
the media
advertising and publicity

Do such institutions know about ÉT?

Do such institutions subscribe to ET?
October (see pp. 12-13). In this Janus-faced approach I have argued that World English (all English everywhere, of whatever kind) is too large and too diffuse to be subject to legislation and the pruning of purists. The only kind of English that is even minimally responsive to campaigns and caveats is the standard, literacy-linked core of English (if 'core' is the right metaphor here).

Many people see this core as not just a medium of communication but a vehicle of civilization. Godfrey Talbot espouses this view, writing on pp. 14-16 as president of the Queen's English Society, a group centred in the South East of England which fears for the future of what Canadians might call 'a heritage language' (although usually they are talking about Ukrainian and Nootka, rather than English). Within that heritage, Paul Christophersen presents a case for the conservation of Received Pronunciation, both as a standard for British spoken English and as a model for the learning of English in Europe.

By way of contrast, our other three special features pursue quite different ends. Liz Gill not only describes but lives in her article the style of popular journalism, while Edmund Weiner with academic care outlines the future of the Oxford English Dictionary, and Gary Imhoff defends the proposed English-language amendment to the US constitution. It may well be that, across the board, this issue of $E T$ is the most stylistically varied to date - with a minimum of editorial effort to homogenize the brew.

The brew, therefore, has many flavours. Post $\mathcal{E}$ Mail in particular is vibrant with replies and rebuttals, in which sexist language, Esperanto, spelling reform, usage issues and varieties of English rub shoulders with literacy, dictionaries and dialects, and a proposal that English is the natural language for Europe. Is it? It would be good to hear from some Europeans on that one.

Tom McArthur

The editorial policy of English Today is to provide a focus or forum for all sort of news and opinion from around the world. The points of view of individual writers are as a consequence their own, and do not reflect the opinion of the editorial board. In addition, wherever feasible, ET leaves unchanged the orthography (normally British or American) and the usage of individual contributors, although the editorial style of the magazine itseif is that of Cambridge University Press.

Letters to the editor should be addressed to a branch of Cambridge University Press (for forwarding), or directly to:

Dr Tom McArthur Editor, English Today

22-23 Ventress Farm Court

Cherry Hinton Road

CAMBRIDGE CB1 4HD

England

Cover illustration by Marlborough Design, Oxford. 